\title{
Perception of Ecological Welfare from the Recycling of Agricultural Resources and Its Influencing Factors
}

\author{
Xiaoyuan Geng \\ College of Economics \& Management, Heilongjiang Bayi Agricultural University, Daqing 163319, China
}

Corresponding Author Email: gengxiaoyuan@ @yau.edu.cn

https://doi.org/10.18280/ijsdp.150413

Received: 10 Januray 2020

Accepted: 1 April 2020

\section{Keywords:}

recycling of agricultural resources, ecological welfare, perception, sequential logistics regression $(S L R)$

\begin{abstract}
This paper attempts to disclose how micro-subjects perceive the ecological welfare from the recycling of agricultural resources, and what are the factors affecting the perception. Firstly, the current status of modern agriculture was introduced, and the connotation of ecological welfare was explained in details. Then, the ecological welfare was divided into three aspects, namely, air quality change, water quality change, and farmland quality change. Meanwhile, eleven variables were selected, including seven personal variables and four external variables. The research data were collected through a questionnaire survey on farmers in Heilongjiang Province, China, and subjected to sequential logistics regression (SLR). The results show that the farmers could perceive the ecological welfare, which stems from the recycling of agricultural resources, much more effectively, if the recycling is industrialized and up-scaled, well-educated professional farmers are trained, and rural infrastructure is improved. The research findings provide a guidance for farmers to engage in the recycling of resources.
\end{abstract}

\section{INTRODUCTION}

The recycling of agricultural resources has significant ecological benefits in terms of water environment, farmland quality, and air environment. With the growing awareness of the ecological functions of agriculture, the concept of ecological welfare has emerged, which expresses the ecological benefits of a specific subject. It is an important task to fully integrate ecological welfare with the development of modern agriculture.

Currently, the studies on ecological welfare mainly concentrate on three aspects: connotation, industrial realization, and measurement.

(1) Ecological welfare is the ecological version of social welfare, which supplements and improves social welfare. With the deepening of relevant research, the connation of ecological welfare continues to expand towards ecological welfare demand, ecological welfare recipient, and the integration between ecological welfare and material welfare.

(2) Industry is an important carrier for the realization of ecological welfare. Antón-Herrero et al. [1] summed up the relationship between welfare and the eco-environment of agriculture. Barragán et al. [2] probed deep into ecological welfare from the perspective of socialization.

(3) The measurement of ecological welfare can be traced back to 1929. Andrew, Nick, and Stefan Bergheim are the pioneers in measuring ecological welfare [3]. Later, BarreiroVescovo et al. [4] put forward the index of economic wellbeing (IEWB). Besides, the New Economic Foundation, a British thinktank, designed the happy planet index (HPI), marking the first attempt to combine environmental impact and welfare to measure the performance of our living environment $[5,6]$. Chen et al. [7, 8] argued that HPI does not consider the negative externalities of environmental damage, and developed a new index called environmentally responsible happy nation index (ERHNI).

To sum up, the scholars engaging in ecological welfare mostly focus on the connotation, industrial realization, and measurement of ecological welfare $[9,10]$. There is no report on how micro-subjects perceive the ecological welfare from the recycling of agricultural resources, or what are the factors affecting the perception.

To make up for the gap, this paper firstly introduces the current status of modern agriculture, and explains the connotation of ecological welfare. Then, sequential logistics regression (SLR) was adopted to analyze the perception of ecological welfare from the recycling of agricultural resources and its influencing factors. Based on the analysis results, several highly operable suggestions were made to industrialize and realize the scale effect of the recycling of agricultural resources.

\section{METHODOLOGY}

The SLR is a special tool to solve regression problems, where the explained variables are discrete and the explanatory variables are continuous or discrete [11-13]. In this paper, the change in each of the three aspects of ecological welfare (air quality, water quality, and farmland quality) is scored by farmers as follows: "worse $=1$ ", "the same $=2$ ", and "better $=3$ ". The scores thus obtained from a multi-class sequential data, which cannot be effectively analyzed by stepwise regression or multiple regression. Therefore, the SLR was introduced to systematically analyze the farmers' perception of ecological welfare and its influencing factors: 


$$
y_{i}=\alpha+\sum_{i=1}^{n} \beta_{i} Z_{k i}+\varepsilon_{i}
$$

where, $y_{i}$ is the response of farmer $i$ to the ecological welfare from the recycling of agricultural resources $\left(y_{i}=1\right.$ means the response worsens, $y_{i}=2$ means the response remains the same, and $y_{i}=3$ means the response improves); $Z_{k i}$ is the $k$-th factor affecting the response of farmer $i ; \alpha$ is a constant; $\beta_{i}$ is a coefficient; $\varepsilon_{i}$ is a random disturbance reflecting the influence of hidden factors and statistical error [14, 15].

Let $P(y=j \mid x)$ be the probability that the response falls on level $j(j=1,2,3)$. Then, the probability that the response falls on or below $j(j=1,2,3)$ can be expressed as $P(y \leq j \mid x)=P(y=1 \mid x)+\ldots+P(y=j \mid x)$. The cumulative probability that the response falls on or below $j$ was subjected to logit transform:

$$
\begin{gathered}
\log i t P_{j}=\log i t[P(y>j \mid x)]=\ln \frac{P(y>j \mid x)}{1-P(y>j \mid x)} \\
j=1,2
\end{gathered}
$$

The logistics regression of sequential classification results can be defined as:

$$
\begin{gathered}
\log i t P_{j}=\log i t[P(y>j \mid x)]=-\alpha_{j}+\sum_{i=1}^{p} \beta_{i} x_{i} \\
j=1,2
\end{gathered}
$$

Formula (3) can be rewritten as:

$$
P(y \leq j \mid x)=\frac{1}{1+\exp \left(-\alpha_{j}+\sum_{i=1}^{p} \beta_{i} x_{i}\right)}
$$

Then, level $k$ was divided into two classes: $\{1, \ldots, j\}$ and $\{j+1, \ldots, k\}$. Let $p$ be the logarithm of the advantage of the cumulative probability that the response falls on the latter class over the cumulative probability that the response falls on the former class. Hence, the above model is called the cumulative advantage model.

The cumulative advantage model of the sequential classification results contains $(k-1)+p$ parameters, in which $\alpha_{i}$ and $\beta_{i}$ are estimated parameters. For any $j, \log i t P_{j}$ is a linear function of the explanatory variable $x: P(y \leq 1 \mid x)<$ $P(y \leq 2 \mid x)<\ldots<P(y \leq k \mid x)$. It can be derived that $\alpha_{1}<\alpha_{2}<\ldots<\alpha_{k}$, where $\alpha_{i}$ is the division coefficient splitting the distribution. Then, the parameters were estimated by maximum likelihood method:

$$
\begin{gathered}
P(y=j \mid x)=P(y \leq j \mid x)-P(y \leq j-1 \mid x) \\
=P\left(-\alpha_{j}+\sum_{i=1}^{p} \beta_{i} x_{i}<u<-\alpha_{j-1}+\sum_{i=1}^{p} \beta_{i} x_{i}\right) \\
=\frac{1}{1+\exp \left(-\alpha_{j}+\sum_{i=1}^{p} \beta_{i} x_{i}\right)}-\frac{1}{1+\exp \left(-\alpha_{j-1}+\sum_{i=1}^{p} \beta_{i} x_{i}\right)} \\
j=1,2
\end{gathered}
$$

where, $p_{i}$ is the probability of farmer $i$ 's response to ecological welfare; $\alpha$ is a constant; $\beta_{i}$ is a regression coefficient [16].

\section{DATA SOURCES AND VARIABLE DESCRIPTION}

Behavioral economics hold that the attitude of a subject depends on his/her perception of behavioral results [17]. The change of attitude reshapes behavioral motives, which in turn affect the behavioral process and effect. This is largely consistent with the theory on farmer behavior. The cognition, motives and attitude of farmers are affected by common features like bounded rationality, vulnerability to risk, and low income. According to Lewin's behavior model, the subject's behavior is influenced by two sets of factors: personal features, and external impacts $[18,19]$.

Therefore, this paper classifies the factors affecting farmer's perception of the ecological welfare from the recycling of agricultural resources into two categories: personal variables and external variables. Seven personal variables were selected, namely, gender, age, education, years of farming, part-time job $(\mathrm{Y} / \mathrm{N})$, participation in training $(\mathrm{Y} / \mathrm{N})$, and participation in specialized farmer cooperative $(\mathrm{Y} / \mathrm{N})$. Four external variables were selected, including nearby rivers or reservoirs $(\mathrm{Y} / \mathrm{N})$, recycling infrastructure of agricultural resources $(\mathrm{Y} / \mathrm{N})$, distance to the nearest fair/market, and satisfaction of nearby highways.

\subsection{Data sources}

This paper selects farmers in Heilongjiang Province, China as the objects. Relying on modern agricultural technology, Heilongjiang is a major agricultural production base. The farmers from Heilongjiang are ideal objects for our research on the farmers' perception of the ecological welfare from the recycling of agricultural resources.

The authors issued 700 questionnaires to farmers in Heilongjiang, asking them about their perception of the ecological welfare from the recycling of agricultural resources. A total of 681 questionnaires were returned. Among them, 616 questionnaires were found valid. Therefore, the questionnaires of 616 farmers from Heilongjiang were subjected to further analysis.

Our data analysis and modelling were based on the SLR, which is capable of handling diverse data. The SLR could analyze the data well, even if they are collected by ordinary questionnaires. Therefore, our questionnaire was designed as an ordinary one, without using the Likert scale [20].

The robustness of our questionnaire was verified through reliability analysis. The commonly used reliability coefficients include Cronbach's alpha $(\alpha)$, Alpha, split-half reliability, Kuder-Richardson formula, and Guttman split-half reliability [21]. This paper selects the Cronbach's $\alpha$ to measure the reliability of our questionnaire. In general, the reliability is low at $\alpha<0.35$, medium at $0.35 \leq \alpha<0.70$, and high at $0.70 \leq \alpha$. In other words, a questionnaire is stable enough for analysis, if its Cronbach's $\alpha$ is above 0.7 [22].

The reliability of the 616 questionnaires were analyzed on SPSS 22.0. The Cronbach's $\alpha$ was found to be 0.7261 , indicating that our survey results are sufficiently robust.

\subsection{Descriptive analysis of variables}

The ecological welfare from the recycling of agricultural resources is mainly manifested as the optimization and improvement of agricultural environment in all dimensions. The factors that affect the ecological welfare cover personal features of farmers (e.g. gender, age, education, and years of 
farming) and external factors (e.g. infrastructure, surrounding environment, and national policies). Through careful consideration, three explained variables and eleven explanatory variables (Table 1) were selected for our analysis.

\subsubsection{Explained variables}

The explained variables include the farmer's response to the change in each of the three aspects of ecological welfare (air quality, water quality, and farmland quality). At present, many agriculture resources are utilized improperly, causing serious "stereo" pollution to waterbody, farmland, and the air. Therefore, the farmer's responses to air quality change, water quality change, and farmland quality change were selected to measure the ecological functions of the recycling of agricultural resources in a comprehensive manner [23-25]

\subsubsection{Explanatory variables}

\section{(1) Gender}

This variable reflects the difference between male and female farmers in the response to the ecological welfare from the recycling of agricultural resources.

(2) Age

This variable reflects how experience affects the farmer's response to the ecological welfare from the recycling of agricultural resources.

(3) Education

This variable reflects how cultural quality and learning ability affects the farmer's response to ecological welfare.

(4) Years of farming

This variable theoretically measures the ability of the farmer to perceive the changes in the "stereo" agricultural environment.

(5) Part-time job (Y/N)

This variable reflects the difference between professional and non-professional agricultural producers in the perception of ecological welfare.
(6) Participation in training $(\mathrm{Y} / \mathrm{N})$

This variable reflects how the mastery of techniques affects the farmer's response to the ecological welfare, because the recycling of agricultural resources is both technology- and labor-intensive.

(7) Nearby rivers or reservoirs $(\mathrm{Y} / \mathrm{N})$

This variable reflects how the changes of nearby environment affects the farmer's perception of ecological welfare.

(8) Recycling infrastructure of agricultural resources (Y/N)

This variable demonstrates the role of infrastructure, which is essential to the recycling of agricultural resources, in the farmer's perception of ecological welfare.

(9) Participation in specialized farmer cooperative $(\mathrm{Y} / \mathrm{N})$

This variable reflects how specialized farmer cooperative, which greatly promotes the recycling of agricultural resources, the farmer's response to ecological welfare.

(10) Distance to the nearest fair/market

This variable reflects how convenient it is for the farmer to acquire information.

(11) Satisfaction of nearby highways

This variable reflects how nearby traffic conditions, which greatly affects the farmer's participation in the recycling of agricultural resources, influence the farmer's perception of ecological welfare.

According to the values and descriptive features of explained and explanatory variables in Table 1, the farmers being surveyed were 51.24 on average, i.e. they have a certain experience; the education scores averaged at 2.93 , i.e. most farmers are graduates of junior high school, with relatively poor cultural quality and learning ability; the mean years of farming was 30.59 , i.e. the farmers boast rich knowledge and experience of agricultural production; the nearest fair/market was about $1-2 \mathrm{~km}$ away, and the satisfaction of nearby highways averaged at 2.6743 , i.e. the farmers are neutral about or slightly satisfied with the nearby highways.

Table 1. The meanings of variables and results of descriptive analysis

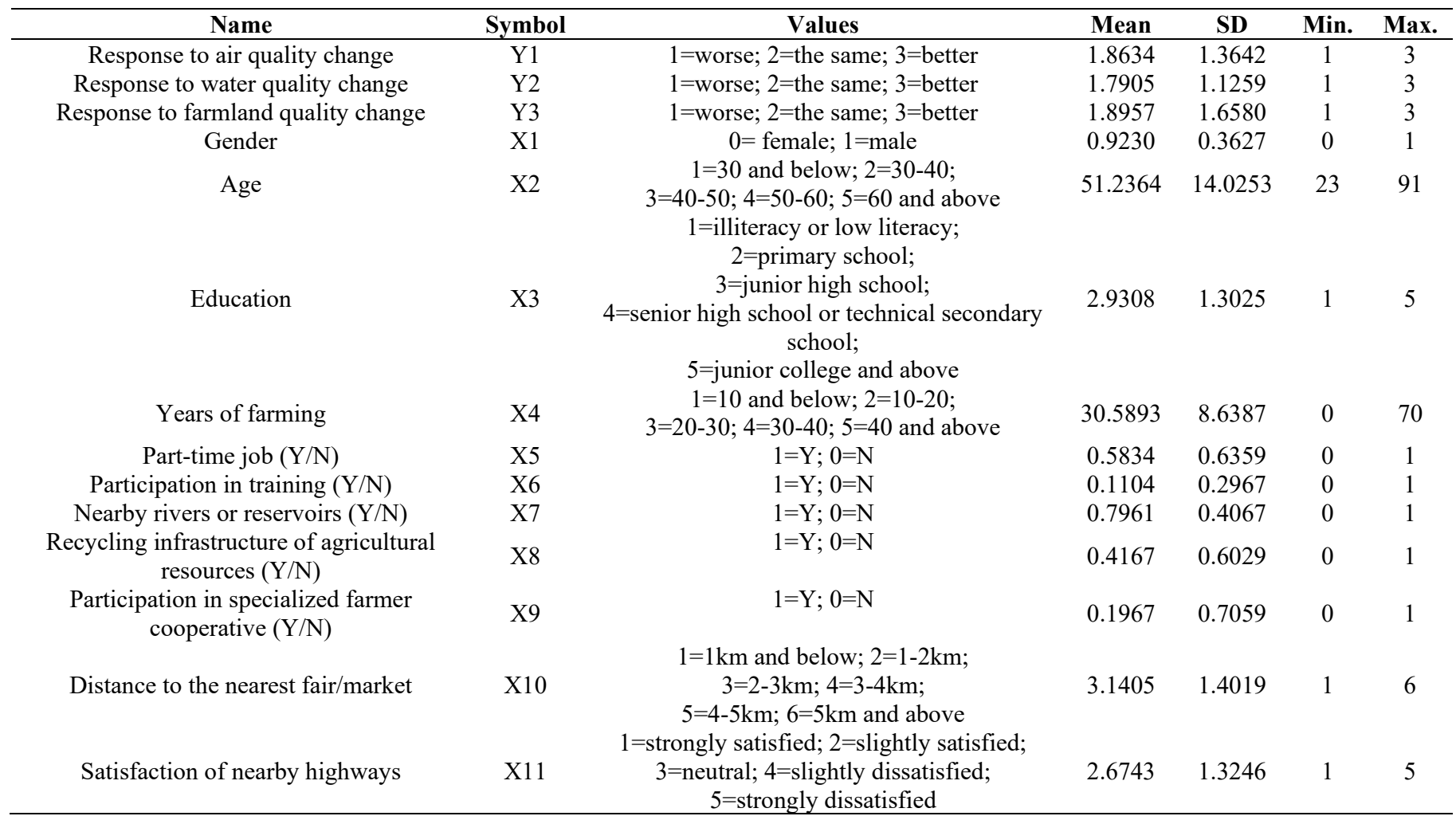




\section{RESULTS AND ANALYSIS}

\subsection{Farmers' perception of ecological welfare from the recycling of agricultural resources}

According to the results of descriptive analysis, the farmers' perception of ecological welfare during the recycling of agricultural resources was divided into three aspects:

(1) Perception of air quality change

Among the 616 respondents, $29.36 \%$ held that rural air quality worsened in recent years, $44.57 \%$ believed that rural air quality remained the same, and only $26.07 \%$ recognized that rural air quality improved due to the recent transform and reuse of agricultural resources. Overall, the farmers had a low perception of ecological welfare in terms of air quality change. This means the recycling of agricultural resources has substantially changed the air quality.

(2) Perception of water quality change

Among the 616 respondents, $45.81 \%$ held that rural water quality worsened in recent years, $27.59 \%$ believed that rural water quality remained the same, and only $26.01 \%$ recognized that rural water quality improved due to the recent recycling of agricultural resources. Overall, the farmers had a low perception of ecological welfare in terms of water quality change. The recycling of agricultural resources has not markedly improved the water environment in rural areas.

Compared with air quality change, water quality change is closely associated with agricultural production. Therefore, the farmers are more sensitive to water quality change than air quality change. That is why $44.57 \%$ believed that rural air quality remained the same, and $45.81 \%$ held that rural water quality worsened in recent years. However, the proportions of farmers who thought that the air quality and water quality have improved were both below $30 \%$, indicating that the farmers had a low perception of ecological welfare in terms of air quality change and water quality change.

(3) Perception of farmland quality change

Among the 616 respondents, $27.13 \%$ held that farmland quality worsened in recent years, $50.41 \%$ believed that farmland quality remained the same, and only $22.46 \%$ recognized that farmland quality improved due to the recent recycling of agricultural resources. Overall, the farmers had a low perception of ecological welfare in terms of farmland quality change. The recycling of agricultural resources has not reached a scale effect on improving the non-point source agricultural pollution.

To sum up, the farmers had relatively low perception of ecological welfare, although local governments have formulated many policies on the recycling of agricultural resources and rural eco-environment governance. There is still ample room to improve the ecological welfare of farmers.

\subsection{Influencing factors of farmers' response to ecological welfare}

The multicollinearity of the explanatory variables was tested, using the calculation module of variance inflation factor (VIF) in SPSS 22.0. The results show that the explanatory variables were not linearly correlated. Furthermore, the model was found to have a high goodnessof-fit, for all explanatory variables passed the significance test at the 5\% level. In addition, these variables also passed the test of parallel lines in SPSS 22.0.

On this basis, the SLR models were constructed for farmers' perceptions of air quality change, water quality change, and farmland quality change, and analyzed by the Ordinal Regression module in SPSS 22.0. Based on the analysis results (Table 2), the factors that affect the farmers' perception were discussed as follows:

\subsubsection{Factors affecting farmers' perception of air quality change}

The regression results of model 1 show that, during the recycling of agricultural resources, the perception of air quality change has a significant negative correlation with education (significant at the 5\% level), and a significant positive correlation with years of farming and satisfaction of nearby highways (significant at the $10 \%$ level).

According to the variable values in Table 1, when agricultural resources are being recycled, every level of increase in education reduces the score of air quality change by $0.675 \%$; long years of farming and improved traffic conditions can effectively enhance the farmers' favorable attitude to air quality change. Therefore, the farmers' perception of ecological welfare can be greatly improved by training professional farmers and promoting infrastructure.

Meanwhile, the other eight variables showed insignificant impacts on the perception of air quality change. Their influence on farmer's perception of air quality change can be neglected.

4.2.2 Factors affecting farmers' perception of water quality change

The regression results of model 2 show that, during the recycling of agricultural resources, the perception of water quality change has a significant negative correlation with gender (significant at the 5\% level) and education (significant at the $10 \%$ level), and a significant positive correlation with the distance to the nearest fair/market and satisfaction of nearby highways (significant at the $10 \%$ level).

According to the variable values in Table 1, when agricultural resources are being recycled, male farmers with relatively good education had low perception and recognition of water quality change; if there is a fair/market nearby and the traffic conditions are good, the farmers tend to perceive and recognize water quality change well. Therefore, the farmers' perception of ecological welfare can be greatly improved by stepping up the construction of market infrastructure.

Meanwhile, the other seven variables showed insignificant impacts on the perception of water quality change. Their influence on farmer's perception of water quality change can be neglected.

\subsubsection{Factors affecting farmers' perception of farmland quality change}

The regression results of model 3 show that, during the recycling of agricultural resources, the perception of farmland quality change has a significant negative correlation with years of farming (significant at the 5\% level), recycling infrastructure of agricultural resources (significant at the $10 \%$ level), and participation in specialized farmer cooperative (significant at the $5 \%$ level).

According to the variable values in Table 1, when agricultural resources are being recycled, the farmers who had engaging in farming for many years were sensitive to the changes in the "stereo" agricultural environment, and tend to perceive the worsening of farmland quality. In our survey, $59.35 \%$ of respondents replied that his/her village has no 
recycling infrastructure of agricultural resources; $86.00 \%$ of them answered that he/she had not participated in specialized farmer cooperative. This greatly limits the farmers' perception of farmland quality change.
Meanwhile, the other seven variables showed insignificant impacts on the perception of water quality change. Their influence on farmer's perception of farmland quality change can be neglected.

Table 2. The SLR results on factors affecting the perception of ecological welfare

\begin{tabular}{|c|c|c|c|c|c|c|c|c|c|}
\hline \multirow[t]{2}{*}{ Variables } & \multicolumn{3}{|c|}{$\begin{array}{c}\text { Response model to air } \\
\text { quality change (model } 1)\end{array}$} & \multicolumn{3}{|c|}{$\begin{array}{l}\text { Response model to water } \\
\text { quality change (model 2) }\end{array}$} & \multicolumn{3}{|c|}{$\begin{array}{l}\text { Response model to farmland } \\
\text { quality change (model 3) }\end{array}$} \\
\hline & $\mathrm{B}$ & SE & Wald & $\mathrm{B}$ & $\mathrm{SE}$ & Wald & $\mathrm{B}$ & $\mathrm{SE}$ & Wald \\
\hline Gender (X1) & 0.507 & 0.425 & 1.117 & $-0.876^{* *}$ & 0.487 & 3.126 & 0.521 & 0.406 & 1.241 \\
\hline Age (X2) & 0.067 & 0.325 & 0.107 & 0.195 & 0.256 & 0.452 & 0.072 & 0.13 & 0.116 \\
\hline Education (X3) & $-0.675^{* *}$ & 0.312 & 11.824 & $-0.712^{*}$ & 0.197 & 8.556 & -0.21 & 0.156 & 0.249 \\
\hline Years of farming (X4) & $1.761^{* *}$ & 0.917 & 4.326 & 0.603 & 0.501 & 1.819 & $-2.988^{* *}$ & 1.21 & 4.216 \\
\hline Part-time job (Y/N) (X5) & -0.395 & 0.455 & 0.927 & -0.301 & 0.348 & 0.513 & -0.187 & 0.254 & 0.551 \\
\hline Participation in training (Y/N) (X6) & -0.035 & 0.856 & 0.113 & -0.203 & 0.506 & 0.147 & 0.054 & 0.359 & 0.014 \\
\hline Nearby rivers or reservoirs $(\mathrm{Y} / \mathrm{N})(\mathrm{X} 7)$ & -0.108 & 0.467 & 0.064 & -0.198 & 0.625 & 0.315 & -0.182 & 0.433 & 0.084 \\
\hline $\begin{array}{l}\text { Recycling infrastructure of agricultural } \\
\text { resources }(\mathrm{Y} / \mathrm{N})(\mathrm{X} 8)\end{array}$ & -0.586 & 0.411 & 2.316 & -0.314 & 0.412 & 1.659 & $-0.543^{*}$ & 0.214 & 2.287 \\
\hline $\begin{array}{c}\text { Participation in specialized farmer } \\
\text { cooperative }(\mathrm{Y} / \mathrm{N})(\mathrm{X} 9)\end{array}$ & 0.101 & 0.529 & 0.107 & -0.547 & 0.536 & 0.842 & $-1.143^{* *}$ & 0.354 & 6.451 \\
\hline Distance to the nearest fair/market (X10) & -0.859 & 1.127 & 0.421 & $1.854^{*}$ & 1.324 & 2.712 & 0.636 & 1.102 & 0.421 \\
\hline \multirow[t]{2}{*}{ Satisfaction of nearby highways (X11) } & $16.253^{* *}$ & 0.752 & 0.019 & $17.874^{*}$ & 0.659 & 0.028 & 0.217 & 1.113 & 0.034 \\
\hline & \multicolumn{3}{|c|}{$\begin{array}{l}\text { Pseudo R-Squared=0.201; } \\
\text { Log Likelihood=420.851; } \\
\text { Chi-Square }=45.718\end{array}$} & \multicolumn{3}{|c|}{$\begin{array}{l}\text { Pseudo R-Squared=0.078; } \\
\text { Log Likelihood=247.346; } \\
\text { Chi-Square=33.063 }\end{array}$} & \multicolumn{3}{|c|}{$\begin{array}{l}\text { Pseudo R-Squared=0.087; } \\
\text { Log Likelihood=253.48; } \\
\text { Chi-Square=39.447 }\end{array}$} \\
\hline
\end{tabular}

To sum up, the following results can be drawn from the regression results: the farmers' perception ability of and sensitivity to the ecological welfare from the improved "stereo" agricultural environment could be effectively enhanced by cultivating professional farmers with relatively good education. Besides, the farmers could perceive ecological welfare much more effectively, if the processing infrastructure of agricultural resources (e.g. nearby roads) is improved.

The farmers' perception of ecological welfare could also be greatly affected by personal variables like age, gender, parttime job $(\mathrm{Y} / \mathrm{N})$, and participation in training $(\mathrm{Y} / \mathrm{N})$, as well as external variables like nearby rivers or reservoirs $(\mathrm{Y} / \mathrm{N})$, and recycling infrastructure of agricultural resources $(\mathrm{Y} / \mathrm{N})$. However, these factors have not exerted an obvious effect on the perception of ecological welfare from the recycling of agricultural resources. This is because the Chinese farmers are generally poorly educated, most technical trainings are merely a formality, and rural infrastructure is still backward. Of course, the underlying reasons should be further researched by relevant subjects.

\section{CONCLUSIONS}

This paper mainly explores the farmers' perception of the ecological welfare from the changes in the "stereo" agricultural environment, which arises from the recycling of agricultural resources, and analyzes the factors affecting the perception process. The influencing factors were divided into personal variables and external variables. The impact degree and direction of each variable were examined in details. The results show that the farmers had a low perception of the ecological welfare from the changes in the "stereo" agricultural environment, including the changes in air quality, water quality, and farmland quality; the recycling of agricultural resources has not reached a scale effect on improving the "stereo" agricultural environment, but plays an important role in improving the quality of air, water, and farmland in rural areas. To unleash the said scale effect, it is necessary to industrialize, scale-up, and standardize the recycling of agricultural resources, thereby improving the farmers' response to ecological welfare. The research results provide important insights on the improvement of agricultural environment in all dimensions.

\section{ACKNOWLEDGEMENTS}

This article was supported by Science Foundation of Heilongjiang Province of China (Youth Science Foundation) Performance Evaluation and Industrial Development Mechanism for Agricultural Waste Recycling in Heilongjiang (QC2016099).

\section{REFERENCES}

[1] Antón-Herrero, R., García-Delgado, C., AlonsoIzquierdo, M., García-Rodríguez, G., Cuevas, J., Eymar, E. (2018). Comparative adsorption of tetracyclines on biochars and stevensite: Looking for the most effective adsorbent. Applied Clay Science, 160: 162-172. https://doi.org/10.1016/j.clay.2017.12.023

[2] Barragán-Fonseca, K., Pineda-Mejia, J., Dicke, M., van Loon, J.J. (2018). Performance of the black soldier fly (Diptera: Stratiomyidae) on vegetable residue-based diets formulated based on protein and carbohydrate contents. Journal of Economic Entomology, 111(6): 2676-2683. https://doi.org/10.1093/jee/toy270

[3] Arumugam, N., Chelliapan, S., Kamyab, H., Thirugnana, S., Othman, N., Nasri, N.S. (2018). Treatment of wastewater using seaweed: A review. International Journal of Environmental Research and Public Health, 15(12): 2851-2868. https://doi.org/10.3390/ijerph15122851

[4] Barreiro-Vescovo, S., de Godos, I., Tomás-Pejó, E., 
Ballesteros, M., González-Fernández, C. (2018). Effect of microalgae storage conditions on methane yields. Environmental Science and Pollution Research, 25(14): 14263-14270. https://doi.org/10.1007/s11356-018-16439

[5] Becker, W., Saisana, M., Paruolo, P., Vandecasteele, I. (2017). Weights and importance in composite indicators: Closing the gap. Ecological Indicators, 80: 12-20. https://doi.org/10.1016/j.ecolind.2017.03.056

[6] Capon, A., Corvalan, C. (2018). Climate change and health: Global issue, local responses. Public Health Research and Practice, 28(4): e2841823. https://doi.org/10.17061/phrp2841823

[7] Chen, E., Ng, Y.K., Tan, Y.F., Toh, J.S.Y. (2017), Environmentally responsible happy nation index: Refinements and 2015 rankings. Social Indicators Research, 134(1): 39-56. https://doi.org/10.1007/s11205-016-1422-2

[8] Snider, A.G., Luo, S., Fusco, E. (2018). Predicting college students' environmentally responsible behavior from personality, political attitudes, and place attachment: a synergistic model. Journal of Environmental Studies and $\quad$ Sciences, $8(3)$ : 290-299. https://doi.org/10.1007/s13412-018-0497-2

[9] Yan, Y., Wang, C., Quan, Y., Wu, G., Zhao, J. (2018). Urban sustainable development efficiency towards the balance between nature and human well-being: Connotation, measurement, and assessment. Journal of Cleaner Production, 178: 67-75. https://doi.org/10.1016/j.jclepro.2018.01.013

[10] Liu, T., Li, Y., Tian, T. (2019). Reinterpreting the connotation of "Sustainability" and the expansion of social policy in China. Sustainability, 11(6): 1814. https://doi.org/10.3390/su11061814

[11] Park, A.R., Mancenido, M.V., Montgomery, D.C. (2019). Separation in D-optimal experimental designs for the logistic regression model. Quality and Reliability Engineering International, 35(3): 776-787. https://doi.org/10.1002/qre.2411

[12] Mansouri, A., Nazari, A., Ramazani, M. (2016). A comparison of artificial neural network model and logistics regression in prediction of companies' bankruptcy (A case study of Tehran stock exchange). International Journal of Advanced Computer Research, 6(24):

81-92. https://doi.org/10.19101/ijacr.2016.624010

[13] van Ackooij, W. (2017). A comparison of four approaches from stochastic programming for large-scale unit-commitment. EURO Journal on Computational Optimization, 5(1-2): 119-147. https://doi.org/10.1007/s13675-015-0051-x

[14] Frisk, M., Jonsson, A., Sellman, S., Flisberg, P., Rönnqvist, M., Wennergren, U. (2018). Route optimization as an instrument to improve animal welfare and economics in pre-slaughter logistics. PloS One,
13(3):

e0193223.

https://doi.org/10.1371/journal.pone.0193223

[15] Garver, M.S., Williams, Z. (2018). Improving the validity of theory testing in logistics research using correlated components regression. International Journal of Logistics Research and Applications, 21(4): 363-377. https://doi.org/10.1080/13675567.2017.1401054

[16] Kang, M.O., Jeon, I.O. (2017). The effects of welfare and institutional factors on organizational commitment. Korea Logistics Review, 27(6): 159-169. https://doi.org/10.17825/klr.2017.27.6.159

[17] Halkos, G., Matsiori, S. (2017). Environmental attitude, motivations and values for marine biodiversity protection. Journal of Behavioral and experimental Economics, 69: 61-70. https://doi.org/10.1016/j.socec.2017.05.009

[18] Zimbardo, P.G. (2016). Carrying on Kurt Lewin's legacy in many current domains Lewin award 2015. Journal of Social Issues, 72(4): 828-838. https://doi.org/10.1111/josi.12196

[19] Bakari, H., Hunjra, A.I., Niazi, G.S.K. (2017). How does authentic leadership influence planned organizational change? The role of employees' perceptions: Integration of theory of planned behavior and Lewin's three step model. Journal of Change Management, 17(2), 155-187. https://doi.org/10.1080/14697017.2017.1299370

[20] Reyes Cruz, J.L., Garzon Castrillon, M.A., Tapia Sanchez, B. (2018). Design and validation of a Likert type scale to establish entrepreneurial characteristics. Dimensión Empresarial, 16(2), 135-160. http://dx.doi.org/10.15665/dem.v16i2.1599

[21] Choa, E., Chun, S. (2018). Originators of reliability coefficients: A historical review of the originators of reliability coefficients including Cronbach's Alpha. Survey Research, 19(2): 73-104. https://doi.org/10.20997/sr.19.2.4

[22] Durand, G. (2019). Incremental validity of the Durand adaptive psychopathic traits questionnaire above selfreport psychopathy measures in community samples. Journal of Personality Assessment, 101(5): 493-502. https://doi.org/10.1080/00223891.2018.1464456

[23] Geng, X.Y. (2018). Straw incineration odor hazard \& disposal mechanism in economic perspective. Chemical Engineering Transactions, 68: 73-78. https://doi.org/10.3303/CET1868013

[24] Moutinho, V., Madaleno, M., Macedo, P., Robaina, M., Marques, C. (2018). Efficiency in the European agricultural sector: Environment and resources. Environmental Science and Pollution Research, 25(18): 17927-17941. https://doi.org/10.1007/s11356-018-2041$\mathrm{Z}$

[25] Geng, X.Y. (2020). On the regional differences in agricultural water use efficiency in china and their convergence. International Journal of Design \& Nature and Ecodynamics, 15(2): 189-196. https://doi.org/10.18280/ijdne.150208 